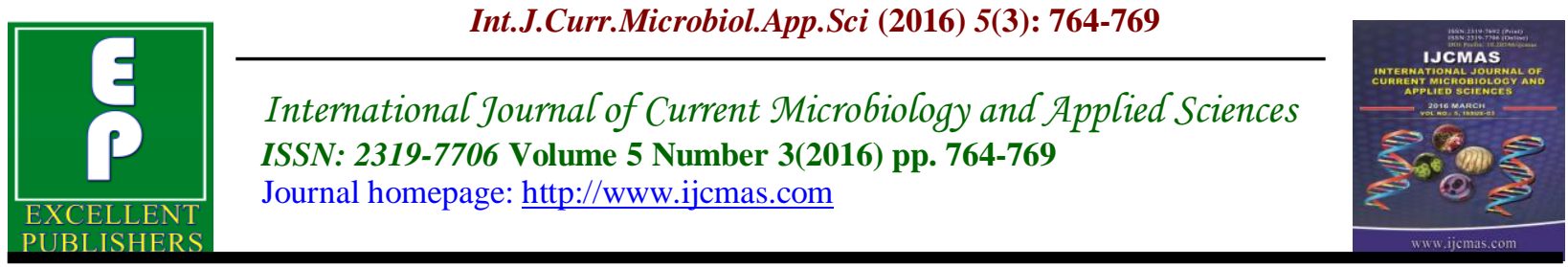

Original Research Article

http://dx.doi.org/10.20546/ijcmas.2016.503.088

\title{
Usefulness of Modified Centrifuged Blood Smear in Diagnosis of Malaria
}

\author{
Shambhavi Singh*, Vivek Agwan, Bhaskar Thakuria and Molly Madan \\ Department of Microbiology Subharti Medical College Subharti University, \\ Meerut, Uttar Pradesh 250005, India \\ *Corresponding author
}

\begin{tabular}{|c|c|}
\hline \multirow{8}{*}{$\begin{array}{l}\text { Ke y w o r d s } \\
\text { Malaria, } \\
\text { Modified } \\
\text { centrifuged blood } \\
\text { smear, } \\
\text { Quantitative } \\
\text { buffy coat, Rapid } \\
\text { antigen detection. }\end{array}$} & A B S T R A C T \\
\hline & \multirow{9}{*}{$\begin{array}{l}\text { Malaria is a heavy burden on tropical communities, a threat to non-endemic } \\
\text { countries, and a danger to travellers. Keeping in mind the seriousness of the } \\
\text { condition and the current availability of various diagnostic facilities; this study is } \\
\text { proposed to compare the peripheral blood smear examinations (thick and thin), } \\
\text { Quantitative Buffy Coat (QBC) examination, Rapid Antigen Detection Test (RDT), } \\
\text { and Modified Centrifuged Blood Smear (MCBS) in clinically suspected cases of } \\
\text { malaria. The study included } 1982 \text { blood samples of patients, clinically suspected to } \\
\text { be of Malaria. All the samples were subjected to Thin Blood Smear, Thick Blood } \\
\text { Smear, QBC, RDT and MCBS. Results were statistically compared considering } \\
\text { MCBS as the standard method. Out of total } 1982 \text { samples, maximum } 81(4.09 \%) \\
\text { were found positive by RDT, followed by MCBS } 66(3.33 \%) \text { QBC } 65(3.28 \%) \text {, } \\
\text { thick blood smear 63(3.18\%) and thin blood smear 58(2.92\%). Addition of } \\
\text { centrifugation step in MCBS increases the sensitivity of the smear technique and at } \\
\text { the same time preserves the morphology of the parasite, giving it more specificity. } \\
\text { MCBS is an easy, cheap and accurate technique and could be adopted for more } \\
\text { reliable diagnosis of malaria in resource-limited settings where expensive } \\
\text { techniques like RDT and QBC are not feasible. }\end{array}$} \\
\hline & \\
\hline & \\
\hline & \\
\hline & \\
\hline & \\
\hline & \\
\hline Article Info & \\
\hline $\begin{array}{l}\boldsymbol{A c} \boldsymbol{c} \\
20 \\
\boldsymbol{A v} \boldsymbol{v} \\
10\end{array}$ & \\
\hline
\end{tabular}

\section{Introduction}

Malaria is the most important protozoal parasitic disease of humans affecting more than one billion people worldwide causing 1 to 3 million deaths each year. Malaria remains today a heavy burden on tropical communities, a threat to non-endemic countries, and a danger to travelers (Fauci et $a l$, 2008). In India about $27 \%$ population lives in malaria high transmission $(\geq 1$ case/1000 population) areas about $58 \%$ in low transmission (0-1 case/1000 population) areas (Park K, 2011).
Lack of proper infrastructure, inability to control the disease in endemic areas, and movement of the population are some important factors responsible for failure to curb malaria (NVBDCP, 2004). The nonspecific nature of the clinical presentation of malaria may lead to over-treatment of malaria in malaria endemic areas; thereby resulting in misdiagnosis and non-treatment of other diseases. The early diagnosis of malaria not only mitigates the sufferings but also reduces the transmission of the parasite in the community. Therefore, precise laboratory diagnosis and species 
identification is very essential (Estacio et al, 1993). In the present study an attempt is made to compare the peripheral blood smear examinations (thick and thin), QBC examination, Rapid Diagnostic Antigen Test and Modified Centrifuged Blood Smear (MCBS) in clinically suspected cases of malaria.

\section{Materials and Methods}

The study was carried out from February 2014 to January 2015. A total of 1982 non repeat blood samples of clinically suspected malaria cases received in central clinical laboratory of tertiary care hospital in Meerut were studied.

Blood samples received were examined by Leishman stained thick and thin blood smears, QBC, pLDH test using Advantage MAL CARD and MCBS.

\section{Inclusion Criteria}

Patients of all age groups and both sexes, presenting with pyrexia as main symptom and attending various outpatient departments or admitted in various wards at Subharti Medical College \& Hospital, Meerut (U.P).

\section{Exclusion Criteria}

Patients who were currently taking antimalarial therapy or who had been treated with antimalarial drugs within the past 2 weeks were excluded from the study.

Informed consent was obtained from all patients, included in this study.

The study has been approved by the research and ethical committee of the institute.

Test procedure of MCBS: Blood samples were collected into heparinized capillary
(Hematocrit) tubes and one end of the tube was immediately sealed using wax. The samples collected in the capillary tubes were centrifuged at $6000 \mathrm{rpm}$ for $5 \mathrm{~min}$. The capillary tube was cut by tube cutter at the required junction (buffy coat layer) (Bhandari et al., 2008).

The following method was attempted: (Bhandari et al., 2008)

The tube was cut just above the buffy coat layer, saving a small column of plasma. The retained plasma column, the buffy coat and an equal quantity of sub buffy coat RBC column were pushed on to the slide; they were gently and uniformly mixed, and smears were drawn. These smears had thickness equivalent to peripheral blood smears, providing an advantage of including the concentration of parasitized RBCs in a thin smear.

This technique combines the advantages of Peripheral Blood Smear and QBC. The parasites are observed directly without any aid and hence this technique is highly specific as far as diagnosis goes. Tube centrifugation adds to the sensitivity of Peripheral Blood Smear and makes it similar to $\mathrm{QBC}$.

Test procedure for thin blood smear, thick blood smear, QBC were as per standard instructions. (Chakraborthy, 2004; Estacio et al., 1993).

Test procedure for Rapid antigen detection was as per instruction manual (J.MITRA).

Calculations: Sensitivity, Specificity, Positive Predictive Value (PPV) and Negative Predictive Value (NPV) of Thin Blood Smear, Thick Blood Smear, QBC, and RDT were calculated by comparing their result with MCBS examination as the 
standard reference in the present study, using 2x2 Table (Park K, 2011).

\section{Results and Discussion}

Out of total 1982 cases, 81 (4\%) were positive by one or more methods i.e Thin Blood Smear, Thick Blood Smear, QBC, RDT and MCBS, while 1901(96\%) cases were negative by all the five methods.

The age of the patients in this study ranged from infants to 89 years old with maximum (43.2\%) between the age group of 20-29 years, with male to female ratio of 1.7: 1 . There was an increase in the incidence of malaria positive cases during June to September period (3.28\%). Out of total 1982 samples, maximum $81(4.09 \%)$ were found positive by RDT, followed by MCBS 66(3.33\%), QBC 65(3.28\%), thick blood smear 63(3.18\%) and thin blood smear $58(2.92 \%)$. (Table 1)

Out of 66 cases positive by MCBS, 60(90.91\%) were positive for Plasmodium vivax, $5(7.58 \%)$ were positive for Plasmodium falciparum and 1 (1.52\%) case was positive for mixed infection, both by Plasmodium vivax and Plasmodium falciparum.

Out of 81 cases positive by Rapid Antigen
Detection Method, 75(92.60\%) were positive for non-P.falciparum species and 6 $(7.41 \%)$ were positive for either P.falciparum or mixed infection.

Out of 58 samples positive by thin blood smear, 52 were identified as P.vivax, 5 were identified as P.falciparum and 1 sample was identified as mixed (P.vivax $+P$.falciparum) infection. (Table 2)

Out of 63 samples positive by thick blood smear, 38 were identified as P.vivax, 4 were identified as P.falciparum and in 21 samples species could not be identified. (Table 2)

Out of 66 samples positive by MCBS, 60 were identified as P.vivax, 5 were identified as P.falciparum and 1 sample was identified as mixed (P.vivax + P.falciparum) infection. (Table 2)

Out of 65 samples positive by QBC, 34 were identified as P.vivax, 4 were identified as P.falciparum and in 27 samples species could not be identified. (Table 2)

Sensitivity, Specificity, PPV and NPV of Thin Blood Smear, Thick Blood Smear, QBC and RDT was compared taking MCBS as the standard method. (Table 3)

Table.1 Number of Cases, Positive by Various Diagnostic Methods. ( $\mathrm{n}=1982)$

\begin{tabular}{|c|c|c|}
\hline Diagnostic Methods & Positive $(\mathbf{n}=\mathbf{1 9 8 2})$ & \% positive \\
\hline RDT & 81 & 4.09 \\
\hline MCBS & 66 & 3.33 \\
\hline QBC & 65 & 3.28 \\
\hline Thick blood smear & 63 & 3.18 \\
\hline Thin blood smear & 58 & 2.92 \\
\hline
\end{tabular}


Table.2 Identification of Species by Various Diagnostic Methods

\begin{tabular}{|c|c|c|c|c|}
\hline & $\begin{array}{c}\text { Thin blood } \\
\text { smear } \\
(\mathbf{n = 5 8})\end{array}$ & $\begin{array}{c}\text { Thick blood } \\
\text { smear } \\
(\mathbf{n = 6 3})\end{array}$ & $\begin{array}{c}\text { MCBS } \\
(\mathbf{n}=66)\end{array}$ & $\begin{array}{c}\text { QBC } \\
(\mathbf{n = 6 5})\end{array}$ \\
\hline P.vivax & 52 & 38 & 60 & 34 \\
\hline P.falciparum & 05 & 04 & 05 & 04 \\
\hline $\begin{array}{c}\text { Mixed }(\boldsymbol{P} . \boldsymbol{f} \\
+\boldsymbol{P} . v)\end{array}$ & 01 & - & 01 & - \\
\hline $\begin{array}{c}\text { Species } \\
\text { unidentifiable }\end{array}$ & 00 & 21 & 00 & 27 \\
\hline Total positive & 58 & 63 & 66 & 65 \\
\hline
\end{tabular}

Table.3 Sensitivity, Specificity, PPV and NPV of Thin Blood Smear, Thick Blood Smear, QBC, RDT Compared to MCBS as the Standard Method

\begin{tabular}{|l|l|l|l|l|}
\hline & Sensitivity & Specificity & PPV & NPV \\
\hline Thin blood smear & $87.88 \%$ & $100 \%$ & $100 \%$ & $99.58 \%$ \\
\hline Thick blood smear & $93.94 \%$ & $99.95 \%$ & $98.41 \%$ & $99.79 \%$ \\
\hline QBC & $92.42 \%$ & $99.79 \%$ & $93.85 \%$ & $99.74 \%$ \\
\hline RDT & $100 \%$ & $99.22 \%$ & $81.48 \%$ & $100 \%$ \\
\hline
\end{tabular}

Figure.1 Equipments Used for Preparation of Modified Centrifuged Blood Smear

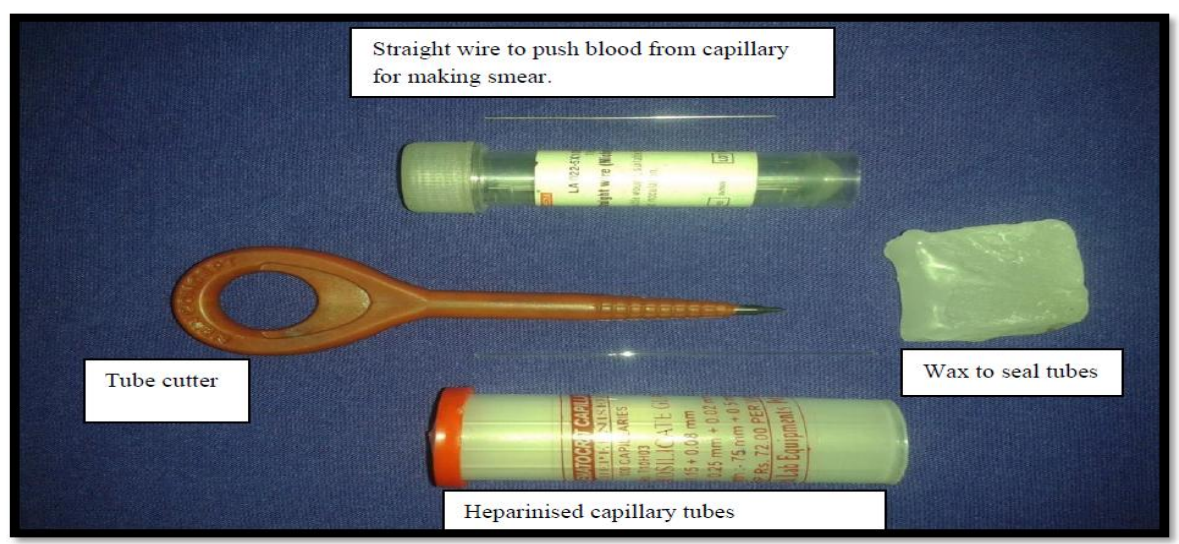

The absolute necessity for rational therapy in the face of rampant drug resistance places importance on the accuracy of malaria diagnosis (Wongsrichanalai et al., 2007). Rapid detection and effective treatment is a pre-requisite for reducing the morbidity and mortality due to malaria. Newer techniques like QBC, Antigen detection assays are rapid, simple and easy to interpret (Parija et al., 2009). The blood smear examination is time tested and optimum method for diagnosis of malaria, but there are some operational difficulties, which results in delay of radical treatment in many cases. On this background the MCBS is relatively inexpensive and gives quite specific results. 
Incidence of malaria cases varies from year to year and the reason for low positivity $(4.09 \%)$ in current study may be due to low incidence of malaria cases in Meerut this year.

In this study MCBS, gave positive result in $66 \%$ cases, which was 8 cases more than thin blood smear. This is distinctly advantageous as expenses for the two methods are comparable. Similar results were obtained in the study by Akhtar et al., in which out of 120 patients, the MCBS detected 6 more cases as malaria positive as compared with the peripheral smear (Akhtar et al., 2010).

Similarly, in another study where the authors used centrifugation-enhanced heparinised capillary tubes for smear preparation and examination found that, out of 100 patients, the modified centrifuged Buffy coat detected 7 more samples as malaria-positive as compared with the conventional smear technique. The addition of centrifugation to the conventional smear technique improved its sensitivity from $86.79 \%$ to nearly $100 \%$ (Bhandari et al, 2008). Specificity and PPV of MCBS is better than thick film, QBC and RDT and is comparable to thin film. Thus MCBS being inexpensive; is distinctly advantageous compared to QBC and RDT. Sensitivity and NPV of MCBS is equal to RDT and is even better than thin film, thick film and QBC. Thus MCBS does not compromise on sensitivity compared to expensive techniques like QBC and RDT. (Table 3)

In conclusion, new simple method of MCBS followed in this study is as sensitive as RDT and eliminates the false positive results of RDT. The modified MCBS is cheap, cost effective, easy to perform and provides a permanent record of the smear. MCBS is also a rapid and accurate technique and could be adopted for reliable diagnosis of malaria in resource-limited settings where RDT and QBC may prove to be costlier options. Some of the equipment like compound microscope, slides and stains are already available in rural health centers. Most of other material required like capillary tubes, centrifuge, tube cutter and steel wire, is also inexpensive and can be easily made available. Hence, it can also be used in malaria diagnosis at the rural level in our country.

\section{References}

Akhtar, S., Maimoon, S., Wilkinson, A., Gowardhan, V., Mahore, S. 2010. Feasible choices in diagnostic methods of malaria. J. Vector Borne Dis., 47: 151-4.

Bhandari, P.L., Raghuveer, C.V., Rajeev, A., Bhandari, P.D. 2008. Comparative study of peripheral blood smear, quantitative buffy coat and modified centrifuged blood smear in malaria diagnosis. Ind. J. PatholMicrobiol, 51: 108-12.

Chakraborthy, P. 2004. Plasmodium and Babesia. In: Textbook of medical parasitology. 1st ed. Kolkata: New Central Book Agency (P) Ltd, pp. 83104.

Estacio, R.H., Edwin, E.R., Cresswell, S., Coronel, R.F., Alora, A.T. 1993. The Quantitative Buffy Coat technique (QBC) in early diagnosis of malaria: The Santo tomas University Hospital experience. Phil. J. Microbiol. Infect. Dis., 22(2): 56-9.

Fauci, A.S., Kasper, D.L., Longo, D.L., Braunwald, E., Hauser, S.L., Jameson, J.L., et al. 2008. Malaria. In: Osler W, editor. Harrison's principles of internal medicine. 17th ed. New York: McGraw Hill, pp. 1280-93. 
Government of Karnataka. 2004. Circular no. NVBDCP:HE, 27: 04-05. Ministry of health and Family Welfare, pp.1-4.

Parija, S., Dhodapkar, R., Elangovan, S., Chaya, D. 2009. A comparative study of blood smear, QBC and antigen detection for diagnosis of malaria. Indian J. Pathol. Microbiol., 52(2): 200-2.

Park, K. 2011. Arthropod-borne infections. In: Textbook of preventive and social medicine. 21st ed. Jabalpur. Banarsidas Bhanot., pp. 231-244.

Park, K. 2011. Park's Textbook of preventive and social medicine. 21st ed. Jabalpur. Banarsidas Bhanot., pp.
$127-128$

Rapid diagnostic kit for detecting infection with $\mathrm{P}$. falciparum and plasmodium Species(P. falciparum/P. vivax/ $P$. malariae/ P. ovale) Malaria Parasite in human Whole blood, j,Mitra \& Co. Pvt. Ltd.

Wongsrichanalai, C., Barcus, M.J., Muth, S., Sutamiharda, A., Wernsdorfer, W.H. 2007. A Review of Malaria Diagnostic Tools: Microscopy and Rapid Diagnostic Test. Am. J. Trop. Med. Hyg., 77(6): 119-27.

\section{How to cite this article:}

Shambhavi Singh, Vivek Agwan, Bhaskar Thakuria and Molly Madan. 2016. Usefulness of Modified Centrifuged Blood Smear in Diagnosis of Malaria. Int.J.Curr.Microbiol.App.Sci. 5(3): 764-769. doi: http://dx.doi.org/10.20546/ijcmas.2016.503.088 